\title{
Situs Inversus during Bariatric Surgery: A Retrospective Analyze
}

\author{
Augusto Tinoco*, Amanda Bussad, Renam Tinoco, Luciana El-Kadre \\ Department of Surgery, São Jose do Avaí Hospital, Rio de Janeiro, Brazil \\ Email: ${ }^{*}$ augtinoco@uol.com.br, el-Kadre@uol.com.br
}

Received 9 August 2015; accepted 23 October 2015; published 26 October 2015

Copyright (C) 2015 by authors and Scientific Research Publishing Inc.

This work is licensed under the Creative Commons Attribution International License (CC BY). http://creativecommons.org/licenses/by/4.0/

(c) (i) Open Access

\begin{abstract}
Background: We were reporting three cases of Situs Inversus in morbidly obese patients that were submitted a laparoscopic gastric bypass (LGBP). The condition itself was not a serious hazard to normal, healthy patients but, may cause difficulties in the diagnosis and management of abdominal pathology. The incidence of surgical disease did not seem to be different as in the general population, but its presentation, diagnosis and the operative procedure were. This was particularly true for laparoscopic surgery. Methods: From January 1999 to June 2015, 3047 morbidly obese patients underwent. Three patients with Situs Inverse (SI), two of the three with Situs Inversus Totalis (SIT), and one with Situs Inversus Parcialis (SIP) were submitted to a laparoscopic Roux-en-Y gastric bypass with no major difficulties. The mean age was 45 years (39 - 49), BMI 37.7 $\mathrm{kg} / \mathrm{m}^{2}$, two of the above patients were female. Results: The LGBP was completed successfully in two of the three patients with SI. The mean duration of surgery was a 167 minutes, ranging from 110 - 210 minutes. The hospital stay was 5 days $(3$ - 8). Conclusions: The benefits of surgery were evident, even in the patients with SI; as there was no need for ICU admission and patients had an early hospital discharge. Morbidly obese patients with SI might be submitted to LGBP. This procedure was feasible and safe when the diagnosis was pre-operatively confirmed, and the surgical team made proper adjustments.
\end{abstract}

\section{Keywords}

Gastric Bypass, Laparoscopy, Morbid Obesity, Situs Inversus, Bariatric Surgery

\section{Introduction}

Situs Inversus is a rare autosomal recessive condition, with an incidence of one in 20,000 among the general population, in which the position of organs is reversed along the sagittal plane [1]. It was first described in 1788,

Corresponding author. 
by students at the Hunterian School of Medicine in London and their teacher, the Scottish physician Matthew Baillie, as a mirror image of the normal [2]. It can be Situs Inversus Parcialis (SIP), is confined to the abdominal or thoracic cavities, or complete, when it involves viscera from both places. The Situs Inversus complete or totalis (SIT) form is characterized by dextrocardia, a left lung with three lobes and the right lung with two. Stomach, spleen and pancreas are right-sided, the liver and gallbladder are to the left. Blood vessels, nerves and lymphatic are also transposed.

The prevalence of morbid obesity (MO) has increased significantly in the world, specially in developed countries [3]. The LGBP is a safe option in the treatment of MO and is an effective method for long-term weight loss [4]. The laparoscopic approach has become the preferred approach for this procedure, due to the lack of major complications and the decreased incidence of complications, like abdominal wall hernias, related to open procedures. Additional benefits to the laparoscopic approach include less postoperative pain and a shorter hospital stay [5] [6] [7].

On the other hand, the laparoscopic approach can pose difficult issues for identification of anatomical variations, especially those occurring less frequent, such as Situs Inversus (SI).

When this anomaly is known in advance, anatomical evaluation should be performed preoperatively using computed tomography (CT) or Magnetic Resonance Imaging (MRI). After detailed evaluation of the images, the surgical team should plan appropriately for the surgical procedure [8] [9]. The vast majority of patients with SI do not have prior knowledge of their condition, leading to an intraoperative diagnosis causing surgical difficulties due to the absence of the overview of the abdominal cavity in laparoscopic surgery.

In order to make this procedure less difficult in patients with SI, it is recommended to use a mirror image, or contralateral placement of trocars and surgical team [10].

We report the surgical approach used in three patients with SI, one case of Situs Inversus Totalis (SIT) and two cases of Situs Inversus Parcialis (SIP).

\section{Methods}

From January 1999 to June 2014, 3047 patients underwent LGBP. Three (0.09\%) of which had SI. The mean age was 45 years (39 - 49), BMI $37.7 \mathrm{~kg} / \mathrm{m}^{2}$, and two being female patients. Epidemiological data of patients, as well as diagnostic procedures are detailed.

Patient \# 1, 49 years, BMI $38.9 \mathrm{~kg} / \mathrm{m}^{2}$, SIP, diagnosis was previously known.

Abdominal CT showed a left hepatic lobe and gallbladder located in the left costal margins, echocardiogram was normal, and Upper GI endoscopy was suggestive for SIP.

Patient \# 2, 39 years, BMI $35 \mathrm{~kg} / \mathrm{m}^{2}$, SIT, previously known diagnosis.

Echocardiography showed dextrocardia, upper digestive endoscopy revealed a sliding hiatal hernia on the right side and the stomach and right lobe of liver with an inverted position (Figure 1 and Figure 2).

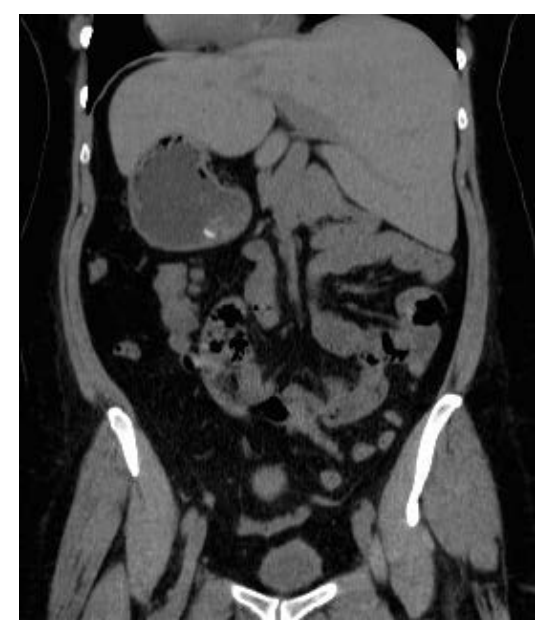

Figure 1. CT of abdomen confirming Situs Inversus, stomach and right lobe of liver with an inverted position. 


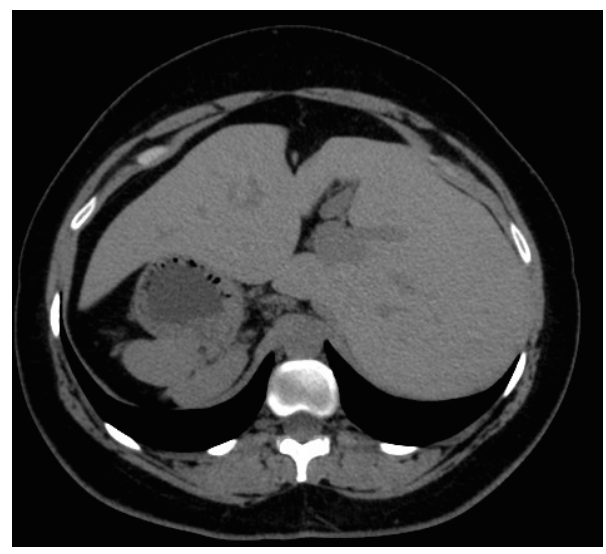

Figure 2. Axial CT image of abdomen showing Situs Inversus.

Patient \# 3, 49 years, BMI $39.2 \mathrm{~kg} / \mathrm{m}^{2}$, SIP, intra-operative diagnosis. The condition of SIP, which was unknown in this patient, the gastric pouch was made without greater difficulties but upon performing the Rouxen-Y we couldn't understand the anatomical situation, especially in identifying the Treitz Angle so we converted the patient to feel secure in performing the jejunojejunostomy.

Patients \# 1 and \# 2 were positioned on reversed Trendelenburg and lateral to the left. Their insertions and the location of instruments were performed according to the mirror image anatomy of the intra-abdominal organs. Six trocars were placed: a $10 \mathrm{~mm}$ trocar, on the midline above umbilical scar (for scope), a $12 \mathrm{~mm}$ on right midclavicular line, $4 \mathrm{~cm}$ below the right costal margin, a $12 \mathrm{~mm}$ on the left anterior axillary line, $4 \mathrm{~cm}$ below the left costal margin, a $5 \mathrm{~mm}$ trocar in the right midclavicular line $2 \mathrm{~cm}$ from the right costal margin, a $5 \mathrm{~mm}$ trocar in the midline, on the epigastrium, and a $12 \mathrm{~mm}$ in the left middle clavicular line, $4 \mathrm{~cm}$ below the left costal margin. The surgeon and camera were on the left side of patient, and first and second assistant on the right.

The procedure involved the making of a $20-30 \mathrm{~mL}$ gastric pouch by sectioning the stomach with three or four load of the linear stapler (45 mm staple line; $3.5 \mathrm{~mm}$ staple height). A \# 22 nasogastric catheter was cut in its distal part and fixed to the anvil of a circular stapler (CEEA $25^{\mathrm{TM}}$, Autosuture, Covidien). The flip top ${ }^{\mathrm{TM}}$ device was broken and fixed, with 3 - 0 polypropylene suture, to the nasogastric tube. The anesthesiologist introduced the anvil through the oral cavity for passage through the esophagus. After laparoscopic visualization, a small incision was made in the terminal esophagus with a delicate grasper, connected to a monopolar cautery system. The nasogastric tube was pushed down until anvil visualization and was disconnected with ultrasonic scissors. The jejunum was sectioned $50 \mathrm{~cm}$ from the Treitz angle with one application of the linear stapler (45 mm staple line; $2.5 \mathrm{~mm}$ staple height). A $150 \mathrm{~cm}$ long Roux limb was used in all patients. A side-to-side jejunojejunostomy was done with one load of the linear stapler (45 mm staple line; $2.5 \mathrm{~mm}$ staple height) and completed with hand-sewn stitches. The distal jejunum was anastomosed to the gastric pouch (G-J anastomosis), performed through the antecolic antegastric route, using the flip-top $25 \mathrm{~mm}$ circular stapler, and tested by injecting $50 \mathrm{~mL}$ of methylene blue through the nasogastric tube.

Both mesenteric defects were closed (Peterson Space and entero-entero anastomoses space), using a running suture, using 3 - 0 polypropylene.

The LGBP was completed successfully in two patients with SI. Conversion was necessary in patient \# 3. The procedure was started using normal procedures but, realizing that the patient was anatomically different making, it necessary to convert. The mean duration of surgery was a 160 minutes, ranging from 110 - 210 minutes. The hospital stay was 5 days (3 - 8). Patients remain under supervision.

\section{Discussion}

The incidence of SI is estimated to be $1 / 9000$, making it a rare condition. It is an autosomal recessive genetic disease in which the position of the organs is reversed along the sagittal plane, affecting both the chest and the abdominal cavity, forming SI totalis or SI parcialis [11].

About seventy percent of patients with this abnormality have other developmental malformations, mainly in- 
volving the gastrointestinal tract, most commonly, biliary atresia and small bowel atresia. Forty percent of patients suffer from malformations outside the digestive tract, congenital heart disease being the most frequent. Early recognition of visceral transposition and their clinical significance is important in the treatment of diseases within this patient population.

The number of laparoscopic bariatric surgeries has increased in recent years, and the LGBP is currently considered the most effective treatment for gastric banding [12]. When operating on patients with this anomaly, surgeons should alter the regular standards and habits to better suit the altered anatomy. As was done in patient \# 3. The condition of SIP, which was unknown in this patient, the gastric pouch was made without greater difficulties but when performing the Roux-en-Y we didn't understand the anatomical situation, especially in identifying the Treitz Angle so the patient was converted so that we could feel more secure in performing the jejunojejunostomy.

Procedures can be safe and effective in the context of SI, as long as attention is paid to the details of left-right reversal. Special attention needs to be paid in the diagnosis and preoperative evaluation of SI, as well as a thorough reorientation of the surgical point of view. We understand that in these operations, the risk of intraoperative complications is higher in comparison to procedures in patients without SI [13]-[15].

Surgery on patients with the syndrome not diagnosed preoperatively provides greater technical difficulty and has a greater likelihood of complications.

The incidence of SI in patients undergoing bariatric surgery in the surgical department of São Jose do Avai Hospital was 3 (0.09\%) out of 3047 patients from January 1999 to June 2014.

\section{Conclusion}

The benefits of the surgery were evident, even in the patients with SI; as there was no need for ICU admission and patients had an early hospital discharge. Morbidly obese patients with SI might be submitted to LGBP [13] [14]. This procedure was feasible and safe when the diagnosis was pre-operatively confirmed, and the surgical team made proper adjustments.

\section{Disclosures}

Drs. Augusto Tinoco, Amanda Bussad and Renam Tinoco have no conflicts of interest or financial ties to disclose.

\section{References}

[1] McKay, D. and Blake, G. (2005) Laparoscopic Cholecystectomy in Situs Inversus Totalis: A Case Report. BMC Surgery, 5, 5. http://dx.doi.org/10.1186/1471-2482-5-5

[2] Brunetti, L. (1878) Scuola di Anatomia Patologica della R. Università di Padova. La tannizzazione dei tessuti animali. Padova: Premiata Tipografia alla Minerva dei fratelli Salmin, 79.

[3] Adams, T.D., Davidson, L.E., Litwin, S.E., Kolotkin, R.L., LaMonte, M.J., Pendleton, R.C., et al. (2012) Health Benefits of Gastric Bypass Surgery after 6 Years. JAMA, 308, 1122-1131. http://dx.doi.org/10.1001/2012.jama.11164

[4] Fobi, M.A. (2004) Surgical Treatment of Obesity: A Review. Journal of the National Medical Association, 96, 61-75.

[5] Aggarwal, R., Hodgson, L., Rao, C., Ashrafian, H., Chow, A., Zacharakis, E., et al. (2008) Surgical Management of Morbid Obesity. British Journal of Hospital Medicin, 69, 95-100. http://dx.doi.org/10.12968/hmed.2008.69.2.28355

[6] Schauer, P.R., Ikramuddin, S., Gourash, W., Ramanathan, R. and Luketich, J. (2000) Outcomes after Laparoscopic Roux-en-Y Gastric Bypass for Morbid Obesity. Annals of Surgery, 232, 515-529. http://dx.doi.org/10.1097/00000658-200010000-00007

[7] Higa, K., Ho, T., Tercero, F., Yunus, T. and Boone, K.B. (2011) Laparoscopic Roux-en-Y Gastric Bypass: 10-Year Follow-Up. Surgery for Obesity and Related Diseases, 7, 516-525. http://dx.doi.org/10.1016/j.soard.2010.10.019

[8] Ahmed, A.R. and O’Malley, W. (2006) Laparoscopic Roux-en-Y Gastric Bypass in a Patient with Situs Inversus. Obesity Surgery, 16, 1392-1394. http://dx.doi.org/10.1381/096089206778663670

[9] Nursal, T.Z., Baykal, A., Iret, D. and Aran, O. (2001) Laparoscopic Cholecystectomy in a Patient with Situs Inversus Totalis. Journal of Laparoendoscopic \& Advanced Surgical Techniques, 11, 239-241. http://dx.doi.org/10.1089/109264201750539772

[10] Catheline, J.M., Rosales, C., Cohen, R., Bihan, H., Fournier, J.L., Roussel, J., et al. (2006) Laparoscopic Sleeve Ga- 
strectomy for a Super-Super-Obese Patient with Situs Inversus Totalis. Obesity Surgery, 16, 1092-1095. http://dx.doi.org/10.1381/096089206778026352

[11] Varano, N.R. and Merklin, R.J. (1960) Situs Inversus: Review of the Literature, Report of Four Cases and Analysis of the Clinical Implications. Journal of the International College of Surgeons, 33, 131-148.

[12] Regan, J.P., Inabnet, W.B., Gagner, M. and Pomp, A. (2003) Early Experience with Two-Stage Laparoscopic Rouxen-Y Gastric Bypass as an Alternative in the Super-Super Obese Patient. Obesity Surgery, 13, 861-864. http://dx.doi.org/10.1381/096089203322618669

[13] Wittgrove, A.C. and Clark, G.W. (1998) Laparoscopic Gastric Bypass for Morbid Obesity in a Patient with Situs Inversus. Journal of Laparoendoscopic \& Advanced Surgical Techniques, 8, 53-55. http://dx.doi.org/10.1089/lap.1998.8.53

[14] Deutsch, G.B., Gunabushanam, V., Mishra, N., Sathyanarayana, S.A., Kamath, V. and Buchin, D. (2012) Laparoscopic Vertical Sleeve Gastrectomy after Open Gastric Banding in a Patient with Situs Inversus Totalis. Journal of Minimal Access Surgery, 8, 93-96. http://dx.doi.org/10.4103/0972-9941.97595

[15] Blegen, H.M. (1949) Cirurgia em Situs Inversus. Annals of Surgery, 129, 244-259. http://dx.doi.org/10.1097/00000658-194902000-00009 